Article

\title{
Hydrocarbon Production from Catalytic Pyrolysis-GC/MS of Sacha Inchi Residues Using SBA-15 Derived from Coal Fly Ash
}

\author{
Chakrit Soongprasit ${ }^{1}$, Duangdao Aht-Ong ${ }^{1,2}$, Viboon Sricharoenchaikul ${ }^{3}{ }^{\mathbb{D}}$, \\ Supawan Vichaphund ${ }^{4}\left(D\right.$ and Duangduen Atong ${ }^{4, *}$ \\ 1 Department of Materials Science, Faculty of Science, Chulalongkorn University, Bangkok 10330, Thailand; \\ chakrit.soong@gmail.com (C.S.); duangdao.a@chula.ac.th (D.A.-O.) \\ 2 Center of Excellence on Petrochemical and Materials Technology, Chulalongkorn University, \\ Bangkok 10330, Thailand \\ 3 Department of Environmental Engineering, Faculty of Engineering, Chulalongkorn University, \\ Bangkok 10330, Thailand; viboon.sr@chula.ac.th \\ 4 National Metal and Material Technology Center, Thailand Science Park, Pathum Thani 12120, Thailand; \\ supawank@mtec.or.th \\ * Correspondence: duangdua@mtec.or.th
}

Received: 30 July 2020; Accepted: 2 September 2020; Published: 8 September 2020

\begin{abstract}
In this work, Sacha inchi (Plukenetia volubilis L.) residues were used as biomass feedstocks in catalytic upgrading pyrolysis with SBA-15, which is a substance synthesized from coal fly ash (CFA), using alkali fusion, followed by hydrothermal treatment (SBA-15-FA). The catalytic activity of fly ash-derived SBA-15 was investigated through the fast pyrolysis of Sacha inchi residues for upgrading the pyrolysis vapors using the analytical pyrolysis-GC/MS (Py-GC/MS) technique. The pyrolysis temperature was set at $500{ }^{\circ} \mathrm{C}$ and held for $30 \mathrm{~s}$ while maintaining the Sacha inchi residues to catalyst ratios of $1: 0,1: 1,1: 5$, and 1:10. In addition, the SBA-15s synthesized from chemical reagent and commercial SBA-15 were evaluated for comparison. The non-catalytic fast pyrolysis of Sacha inchi (SI) mainly consisted of fatty acids (46\%), including chiefly linoleic acid (C18:2). Other compounds present were hydrocarbon (26\%) and nitrogen-containing compounds $(8.7 \%)$, esters $(9.0 \%)$, alcohols $(6.4 \%)$, and furans (3.6\%). The study results suggested that the SBA-15-FA showcased a high ability to improve aliphatic selectivity (mainly $C_{5}-C_{20}$ ) and was found to be almost $80 \%$ at the biomass to catalyst ratio of 1:5. Moreover, the increase in catalyst contents affected the enhancement of hydrocarbons yields and tended to promote the deoxygenation reaction. Interestingly, the catalytic performance of SBA-15 derived from fly ash could be compared to that of the commercial SBA-15 in terms of producing hydrocarbon compounds as well as reducing oxygenated compounds.
\end{abstract}

Keywords: Sacha inchi; coal fly ash; SBA-15; pyrolysis; hydrocarbons

\section{Introduction}

The valorization of biomass residues as biofuels is an interesting phenomenon and has been gaining much attention due to the depletion of fossil fuel reserves, its similarity with traditional fossil fuels in terms of chemical composition, and low pollutant emissions. The potential biofuel resources can be classified into three groups: first-generation feedstocks (i.e., edible vegetable oils and fats), second-generation feedstocks (i.e., non-edible vegetable oils, animal fats, waste cooking oils, agricultural residues, and wastes from food crops), and third-generation feedstocks (i.e., microalgae, bacterial, and terpenes). Direct biofuel production from first-generation feedstocks is certainly uncompetitive; on the other hand, the usage of third-generation feedstocks is limited due to commercialization. Thus, 
the biofuel derived from second-generation feedstocks is intensively focused due to the increase in competition for achieving quality food production and low cost of production [1,2]. Sacha inchi (SI) residues (Plukenetia volubilis L.) have been proposed as one of the potential feedstocks for biofuel production. Sacha inchi is a plant of the Euphorbiaceae family that grows in the Amazonian forest and is now also a native to South East Asia, especially Thailand. Its seeds exhibit high oil content: approximately $35-60 \%$ in terms of weight. Moreover, this oil mainly consists of polyunsaturated fatty acids (PUFA) such as linolenic acid (18:3n-3) and linolenic acid (18:2n-6), which are the precursors of omega- 3 and omega- 6 whose principal properties offer important health and nutritional benefits. Thus, sacha inchi oil is widely used in the food, cosmetic, and pharmaceutical industries. Furthermore, the oil can be considered as an alternative resource for biodiesel production [3,4]. After oil pressing, a large amount of SI residues are produced as a by-product, which leads to disposal problems. The utilization of these wastes by means of a pyrolysis process might solve the disposal problems and consequently generate efficiency energy.

Pyrolysis is a thermal decomposition process that takes place in the absence of oxygen at a moderate temperature (approximately $400-600^{\circ} \mathrm{C}$ ). This process can convert solid organic substances, including biomass from agricultural wastes, oilseed wastes, waste cooking oil, and mainly liquid products (up to $75 \%$ ), which are known as bio-oils. Unfortunately, bio-oil has low-quality features, for example, low heating value, high acidity, low physicochemical stability, and high viscosity due to the presence of high oxygen content (35-40 wt \%). It is chemically comprised of various organic compounds, including water, ketones, aldehydes, carboxylic acids, phenols, and sugar derivatives. Thus, the catalytic fast pyrolysis of biomass is a promising upgrading technology for eliminating oxygenated compounds through deoxygenation reactions, including decarboxylation, decarbonylation, and dehydration. As a result, the formation of hydrocarbon increases, and consequently, the qualities of bio-oil improve [5,6].

To date, numerous catalysts such as metal oxide, microporous, and mesoporous zeolites have been used in catalytic biomass pyrolysis. Among them, ZSM-5, having a three-dimensional pore system consisting of sinusoidal $(5.3 \times 5.6 \AA)$ and straight $(5.2 \times 5.7 \AA)$ channels, showed more effectiveness in terms of promoting catalytic cracking reaction and deoxygenation reactions; therefore, the formation of hydrocarbons, especially aromatics, considerably increased due to their superior properties such as high surface area, shape selectivity, suitable pore structure, and a high number of active sites. Unfortunately, the bio-oil yields significantly decreased when using ZSM-5, which relates to a high density of acid sites. In addition, the fast deactivation of microporous ZSM-5 due to coke formation on its surface is a crucial problem $[7,8]$.

Mesoporous catalysts (e.g., MCM-41 and SBA-15) are exploited in the catalytic pyrolysis of biomass to solve the catalyst deactivation problem and improve the bio-oil yield due to their unique characteristics, including large pore size, tailorable surface area, mild acidity, and high thermal stability [2,9]. Compared to MCM-41, SBA-15 with highly ordered and hexagonally arranged mesopores $(5-30 \mathrm{~nm})$ has thicker wall structures, leading to greater hydrothermal stability. Thus, SBA-15 can be considered a promising mesoporous catalyst for the catalytic up-gradation of bio-oils containing high moisture content and large molecules [9-11].

Traditionally, mesoporous SBA-15 can be synthesized using pure silica sources such as tetraethoxysilane (TEOS), teratramethoxysilane (TMOS), and tetrapropoxysilane (TPOS). To reduce production cost and promote eco-friendly catalyst synthesis, several studies have investigated the possibility of utilizing alternative raw materials for SBA-15 synthesis, including natural mineral wastes [12], spent fluid catalytic cracking (FCC) catalyst [13], palm oil fuel ash [14], bottom ash [15], and fly ash [16-19]. Among these raw materials, fly ash, an abundant by-product generated from coal combustion in power plants, shows a high potential of obtaining high surface area along with inherent acidity properties, owing to its high composition of silica and alumina and because it is easy to collect, highly sustainable, and eco-friendly. To date, fly ash-based SBA-15 mesoporous material has been widely used in $\mathrm{CO}_{2}$ reforming, $\mathrm{CO}_{2}$ capture, $\mathrm{NOx}$ capture, and heavy metal adsorption [12], as shown 
in Table 1. Based on the previous studies and to our knowledge, there are no existing reports that involve the catalytic fast pyrolysis of biomass by using fly ash-derived SBA-15 catalysts.

Table 1. The synthesis methods of SBA-15 derived from industrial wastes and their applications.

\begin{tabular}{|c|c|c|c|c|}
\hline References & Raw Materials & Methods & Zeolites & Applications \\
\hline Kim et al. [12] & Mine tailing & $\begin{array}{c}\text { Alkali fusion and } \\
\text { hydrothermal treatment }\end{array}$ & SBA-15 & $\begin{array}{l}\mathrm{Cu}, \mathrm{Cd} \text {, and } \mathrm{Pb} \\
\text { adsorption }\end{array}$ \\
\hline Yang et al. [13] & $\begin{array}{c}\text { Spent fluid } \\
\text { catalytic catalyst }\end{array}$ & $\begin{array}{c}\text { Alkali fusion and } \\
\text { hydrothermal treatment }\end{array}$ & Al/SBA-15 & Catalysis and adsorption \\
\hline Chong et al. [14] & Palm oil fuel ash & Alkali hydrothermal & Ni/SBA-15 & $\begin{array}{c}\mathrm{CO}_{2} \text { reforming for } \mathrm{H}_{2} \\
\text { production }\end{array}$ \\
\hline Kumar et al. [16] & Coal fly ash & Alkali fusion & MCM-41, SBA-15 & Catalyst \\
\hline Chandrasekar et al. [15] & $\begin{array}{l}\text { Power plant } \\
\text { bottom ash }\end{array}$ & $\begin{array}{c}\text { Alkali fusion and } \\
\text { hydrothermal treatment }\end{array}$ & $\begin{array}{l}\text { MCM-41, SBA-15, } \\
\text { SBA-16 }\end{array}$ & $\mathrm{CO}_{2}$ capture \\
\hline Li et al. [17] & Coal fly ash & Alkali hydrothermal & SBA-15, $\mathrm{NH}_{2}-\mathrm{SBA}-15$ & Lead adsorption \\
\hline Li et al. [18] & Coal fly ash & Alkali hydrothermal & $\mathrm{Fe} / \mathrm{Mn} / \mathrm{Fe}-\mathrm{Mn} / \mathrm{SBA}-15$ & NOx removal \\
\hline $\begin{array}{c}\text { Ściubidło, A., } \\
\text { Majchrzak-Kucęba [19] }\end{array}$ & Coal fly ash & $\begin{array}{c}\text { Alkali fusion and } \\
\text { hydrothermal treatment }\end{array}$ & Na-X, SBA-15, MCM-41 & $\mathrm{NO}_{2}$ capture \\
\hline
\end{tabular}

Therefore, in this work, an SBA-15 mesoporous catalyst was synthesized using an alkali fusion, followed by the hydrothermal method. After the synthesis process, the catalytic performance of fly ash-derived SBA-15 for deoxygenating pyrolysis vapors from the pyrolysis of SI residues was investigated using pyrolysis-GC/MS (Py-GC/MS). The effect of the SI residues to SBA-15 ratio (SI/SBA-15 ratios of 1:1, 1:5, and 1:10) on the pyrolytic products was studied. Additionally, SBA-15-synthesized chemicals and commercial SBA-15 catalysts were also investigated for the purpose of comparison.

\section{Results and Discussions}

\subsection{Characterization of $S B A-15$ Derived from $C F A$}

The small-angle XRD pattern of SBA-15 derived from CFA (SBA-15-FA) demonstrated three characteristic peaks at $2 \theta=0.89^{\circ}, 1.53^{\circ}$, and $1.78^{\circ}$ (Figure 1), which could be indexed to the 100,110 and 200 plans of the highly ordered 2D-hexagonal mesoporous structure (p6mm) [10,11,13]. The SBA-15 prepared from chemical reagents (SBA-15 chemical) and commercial SBA-15 (SBA-15 commercial) exhibited XRD patterns similar to that in SBA-15-FA. This indicates that the supernatant extracted from fly ash can be used as a solution gel to synthesize well-ordered mesoporous materials.

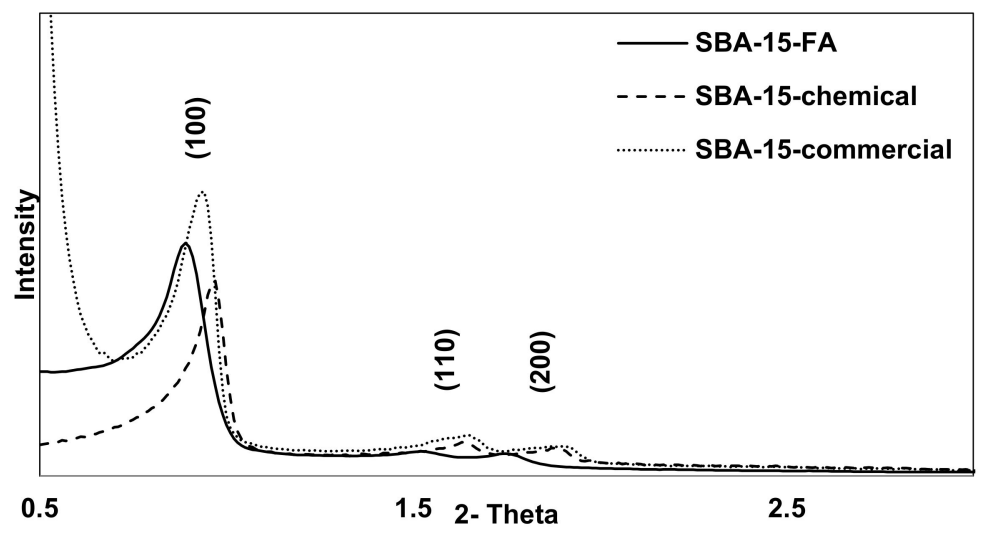

Figure 1. Small-angle of XRD pattern of SBA-15 catalysts.

The $\mathrm{N}_{2}$ adsorption-desorption isotherms and pore size distribution curves of SBA-15-FA, SBA-15-chemical, and SBA-15-commercial catalysts have been displayed in Figure 2. SBA-15-FA 
exhibited type IV adsorption isotherm with type H1 hysteresis loop, which indicates that the mesoporous structure and cylindrical pore channels of SBA-15 can be obtained by using fly ash as a raw material for SBA-15 synthesis. The $\mathrm{N}_{2}$ adsorption isotherms of SBA-15-FA increased sharply over the $\mathrm{P} / \mathrm{P}_{0}$ range of $0.6-0.8$, resulting from the capillary condensation with uniform mesopores $[11,16]$. For other catalysts, they illustrated the similarity in the type IV adsorption isotherm as that of SBA-15 derived from fly ash. Additionally, all SBA-15 catalysts exhibited quite narrow and monomodal pore size distributions, confirming uniform pore size with concentration at around 5-8 $\mathrm{nm}$ (Figure 2b). It was seen that SBA-15-FA revealed that the largest pore size was $7.4 \mathrm{~nm}$.
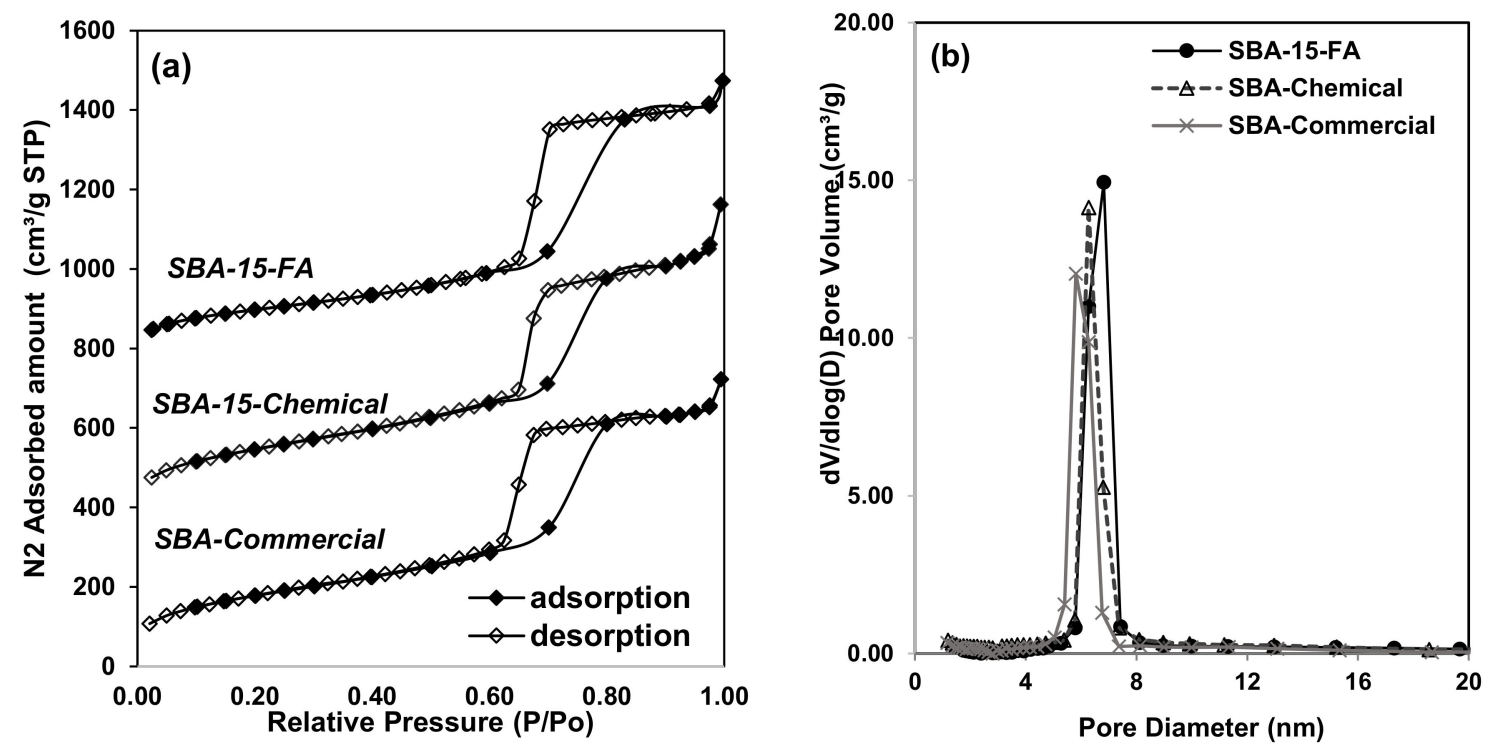

Figure 2. The $\mathrm{N}_{2}$ adsorption-desorption isotherm (a) and pore size distribution curves (b) of SBA-15 catalysts.

The textural properties of SBA-15 catalysts, including specific surface area, total pore volume, pore size, and pore wall thickness, have been showcased in Table 2. Interestingly, the specific surface area and pore volume at $705 \mathrm{~m}^{2} / \mathrm{g}$ and $1.15 \mathrm{~cm}^{3} / \mathrm{g}$, respectively, were found to be greater than the SBA-15 synthesized from chemical reagents. The value obtained corresponded well to the ones presented by the findings of previous works. Li et al. [17] prepared SBA-15 from fly ash using an alkali two-step hydrothermal method with various amounts of $\mathrm{NaOH}$ and reported that the high surface area of $694 \mathrm{~m}^{2} / \mathrm{g}$ with a pore volume of $0.76 \mathrm{~cm}^{3} / \mathrm{g}$ was generated after using $\mathrm{NaOH}$ of $6.4 \mathrm{~g}$ in the dissolution step of fly ash. Meanwhile, Kim et al. investigated the synthesis of SBA-15 from mine tailing, which contained more than $80 \%$ of $\mathrm{SiO}_{2}$. After the alkali fusion and the hydrothermal treatment, the mesoporous silica SBA-15 with a surface area of $513 \mathrm{~m}^{2} / \mathrm{g}$ was successfully synthesized [12]. Recently, Yang et al. [13] successfully hydrothermally synthesized Al-SBA-15 from the spent fluid catalytic cracking catalyst and reported that the highly ordered Al-SBA-15 displayed a high and specific surface area of $742 \mathrm{~m}^{2} / \mathrm{g}$ and a large pore volume of $0.80 \mathrm{~cm}^{3} / \mathrm{g}$. The pore size of SBA-15 catalysts obtained in this study was in the order of SBA-15-FA $(7.4 \mathrm{~nm})>$ SBA-15-chemical $(6.3 \mathrm{~nm})$ $>$ SBA-15-commercial $(5.8 \mathrm{~nm})$, respectively. From this result, it was observed that the SBA-15-FA catalyst had the $\mathrm{Si} / \mathrm{Al}$ ratio of 144.9, as shown in Table 2. The $\mathrm{Al}$ incorporation led to the increase in the pore size of SBA-15 due to the expansion of the aluminosilicate framework. Liang et al. suggested that the d spacing of the (100) plane (d100) changed to the higher values significantly with the initial introduction of aluminum into the SBA-15 structure, which corresponds to the longer $\mathrm{Al}-\mathrm{O}$ bond compared with the $\mathrm{Si}-\mathrm{O}$ bond [20]. Based on these results, it can be concluded that it is possible to use the supernatant extracted from the fused fly ash as silicate and aluminate precursors for the synthesis of mesoporous materials with high surface areas. 
Table 2. Physical and textural properties of the raw material and synthesized SBA- 15 catalysts.

\begin{tabular}{cccccc}
\hline Sample & Si/Al Ratio & $\mathbf{S}_{B E T}\left(\mathbf{m}^{2} / \mathbf{g}\right)$ & Pore Volume $\left(\mathbf{c m}^{\mathbf{3}} / \mathbf{g}\right)$ & Pore Size $^{\mathbf{c}}(\mathbf{n m})$ & Wall Thickness $^{\mathbf{d}}(\mathbf{n m})$ \\
\hline Fly ash & $1.46^{\mathrm{a}}$ & 1.28 & - & - & - \\
SBA-15-FA & $144.9^{\mathrm{b}}$ & 702 & 1.15 & 7.42 & 4.03 \\
SBA-15-Chemical & - & 685 & 1.10 & 6.27 & 4.25 \\
SBA15-Commercial & - & 624 & 1.02 & 5.81 & 5.62 \\
\hline
\end{tabular}

${ }^{a}$ Determined by X-Ray Fluorescence (XRF). ${ }^{b}$ Determined by micro-Energy Dispersive X-ray Fluorescence (micro-EXRF). ${ }^{\mathrm{c}}$ Calculated using the Barrett-Joyner-Halenda (BJH) method. ${ }^{\mathrm{d}}$ Calculated using a $\mathrm{a}_{0}$-pore diameter $\left(\mathrm{a}_{0}=2 \times \mathrm{d}(100) / \sqrt{3}\right)$.

The SEM micrographs of all the SBA-15 catalysts have been presented in Figure 3. SBA-15-FA explicitly revealed that the particles had a rod-like morphology of SBA-15 with a relatively uniform size of less than 3 microns (as shown in Figure 3a). However, SBA-15-FA particles were slightly larger compared to those of SBA-15 synthesized from pure chemical (SBA-15-chemical (Figure 3b)) and SBA-15-commercial (Figure 3c), with a particle size approximately 1-2 $\mathrm{nm}$. The TEM images of SBA-15 synthesized from fly ash, chemical, and commercial SBA-15 have been shown in Figure 4 . The TEM image of SBA-15-FA (Figure 4a) showed relatively uniform well-defined, ordered hexagonal arrays of mesopore channels. This confirms that this mesoporous silica SBA-15 can be synthesized using coal fly ash (CFA) as a raw material. Moreover, the mesoporous fly ash-derived SBA-15 (SBA-15-FA) demonstrated pore characteristics similar to those of SBA-15 prepared from chemical and commercial SBA-15, as shown in Figure 4. The pore diameter of all the samples was less than $10 \mathrm{~nm}$, while the thickness of mesoporous silica walls was estimated to be $5-8 \mathrm{~nm}$, which was in agreement with the $\mathrm{N}_{2}$-adsorption measurements and the XRD results.
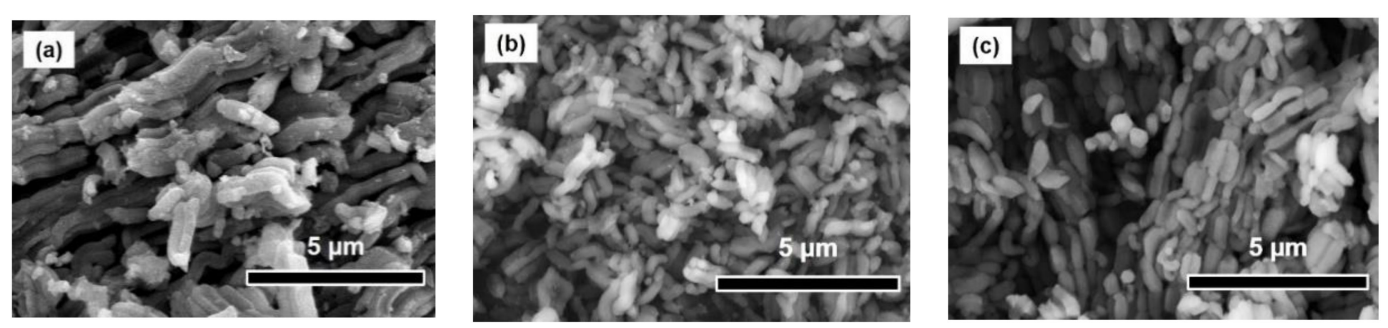

Figure 3. The SEM micrographs of SBA-15 catalysts: (a) mesoporous fly ash-derived SBA-15 (SBA-15-FA); (b) SBA-15-chemical; and (c) SBA-15-commercial.
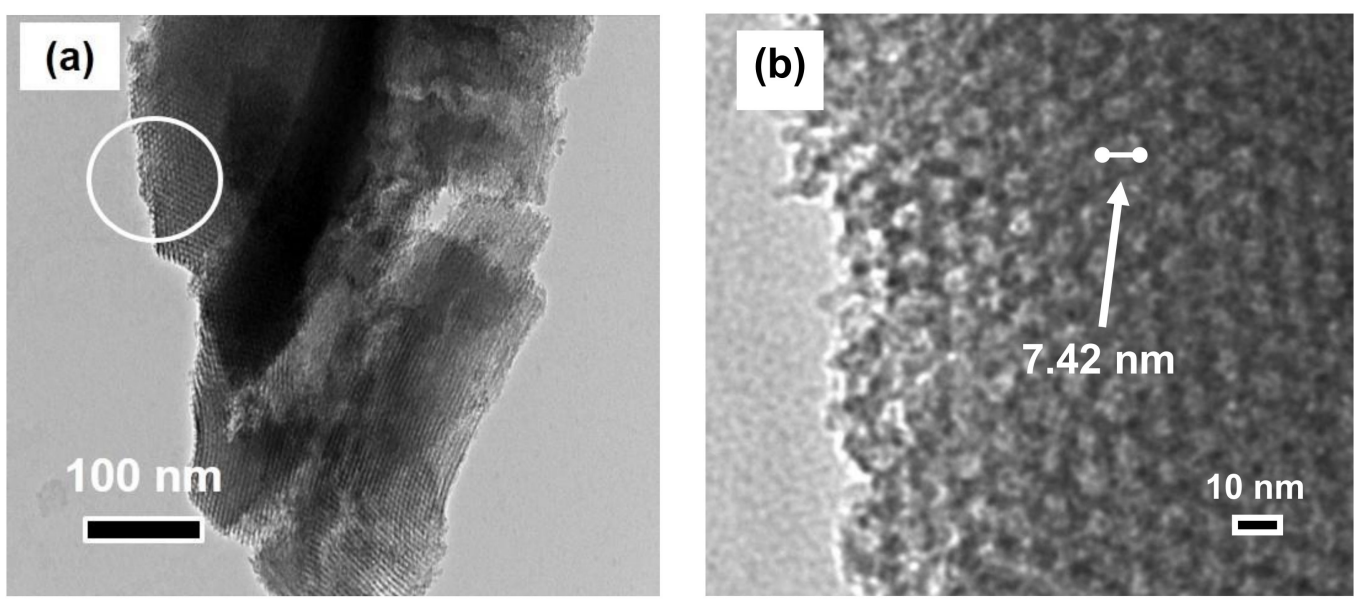

Figure 4. Cont. 

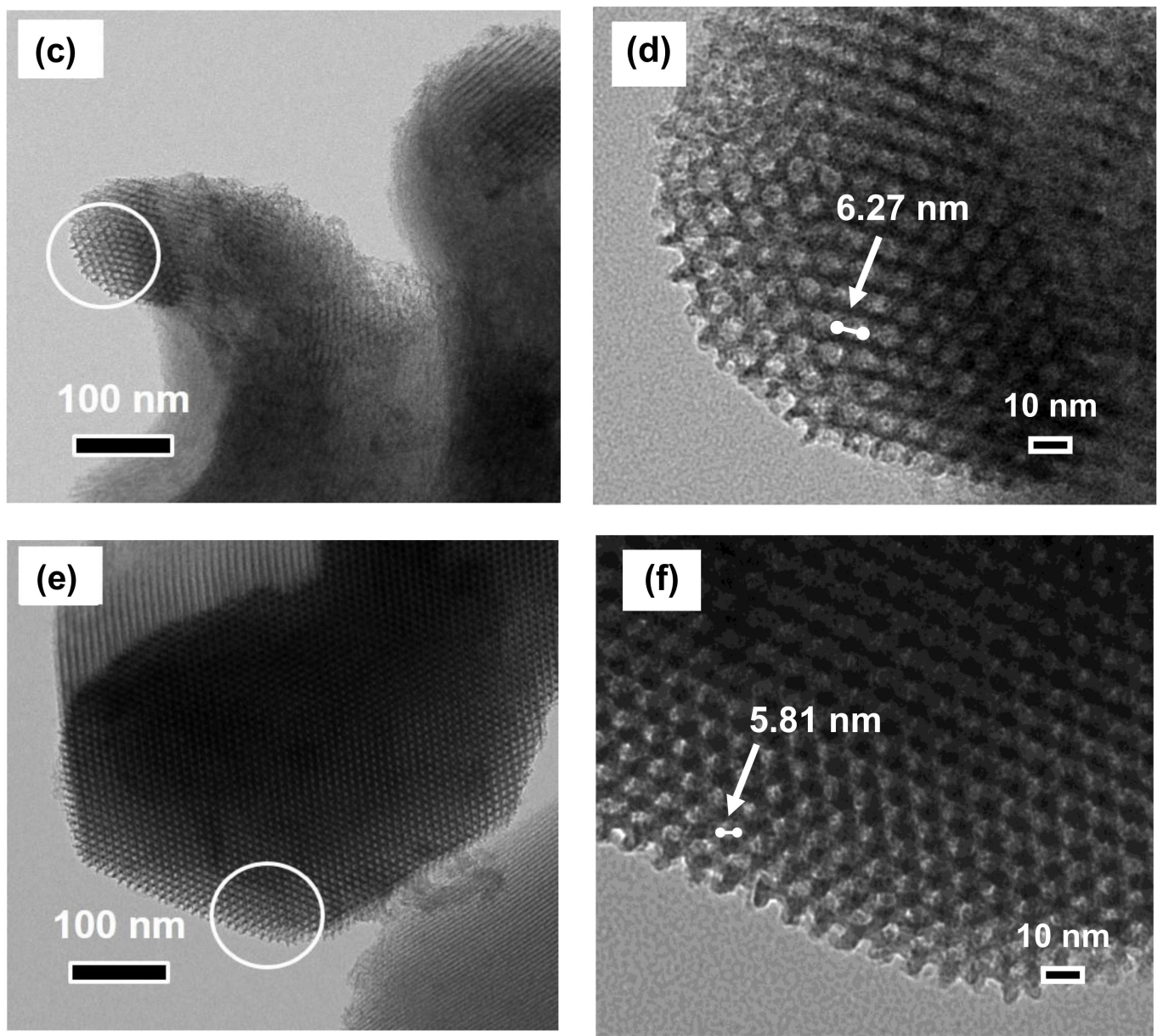

Figure 4. The TEM image of SBA-15 catalysts:

(a,b) SBA-15-FA; (c,d) SBA-15-chemical; and (e,f) SBA-15-commercial.

Figure 5 shows the ammonia temperature-programmed desorption (TPD) results of the SBA-15 synthesized from fly ash (SBA-15-FA), chemical reagents (SBA-15-chem), and commercial (SBA-15-com). Based on the ammonia temperature-programmed desorption $\left(\mathrm{NH}_{3}-\mathrm{TPD}\right)$, the acid site of the acid catalysts could be categorized as weak $\left(100-250{ }^{\circ} \mathrm{C}\right)$, moderate $\left(250-400{ }^{\circ} \mathrm{C}\right)$, or strong $\left(>400{ }^{\circ} \mathrm{C}\right)$ [21]. All the SBA-15 catalysts can be observed as weak, moderate, and strong acid sites in different proportions. The SBA-15-FA catalyst had higher proportions of moderate and strong acidity as a result of the incorporation of $\mathrm{Al}$ ions loaded in the SBA- 15 structure. Additionally, the Fourier transform infrared (FTIR) spectrums of synthesized SBA-15 catalysts with and without pyridine adsorption are given in Figure 6. Pyridine adsorption using the FTIR technique was applied to confirm the incorporation of aluminum into the SBA-15-FA structure. This technique can distinguish between the $\operatorname{Br} \varphi$ nsted and Lewis acid sites. Among SBA-15 catalysts, only the SBA-15-FA sample demonstrated the acidity characteristic peaks in the region of $1400-1700 \mathrm{~cm}^{-1}$ (Figure 6c). The peak that appeared at 1447 and $1545 \mathrm{~cm}^{-1}$ corresponded to the Lewis and $\operatorname{Br} \varphi$ nsted acid sites, respectively, whereas the peaks at $1490 \mathrm{~cm}^{-1}$ are associated with both the Lewis and $\operatorname{Br} \varphi$ nsted acid sites. $[5,20,22,23]$. The number of acid sites of SBA-15-FA catalyst after pyridine adsorption is shown in Table S1. In general, the main compositions of fly ash consist of silica $\left(\mathrm{SiO}_{2}\right)$ and alumina $\left(\mathrm{Al}_{2} \mathrm{O}_{3}\right)[16,24]$. Thus, the $\mathrm{Al}$ ions from the fly ash should be embedded in the framework of SBA-15 derived from fly ash after the synthesis process. On the other hand, SBA-15-chem and commercial (SBA-15-com) exhibited a lower proportion of acidity. 


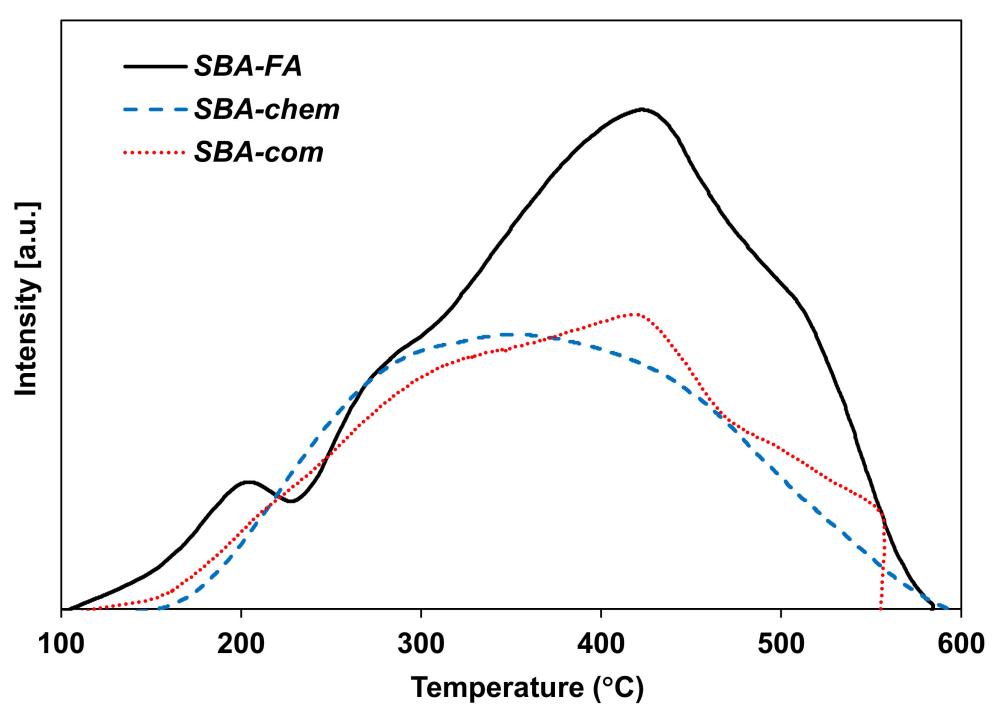

Figure 5. The ammonia temperature-programmed desorption ( $\left.\mathrm{NH}_{3}-\mathrm{TPD}\right)$ profiles of SBA-15 catalysts.
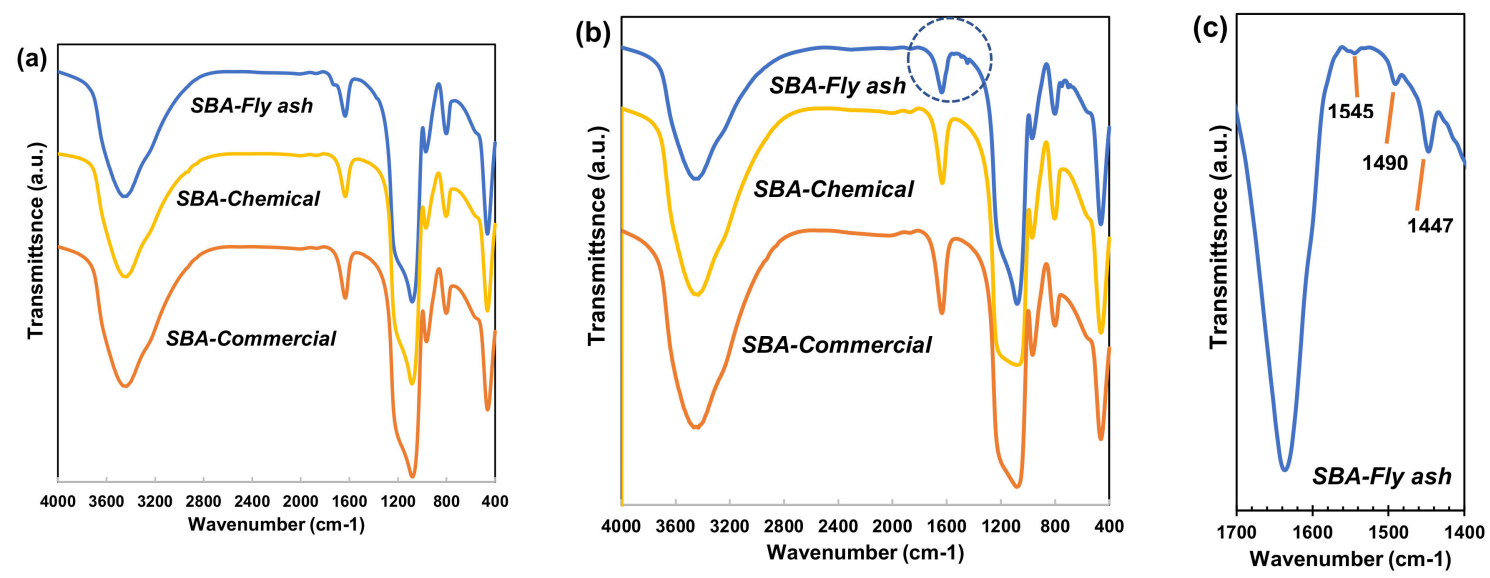

Figure 6. Fourier transform infrared ( FTIR) spectrums of (a) original SBA-15 samples; (b) pyridine-adsorbed SBA-15 samples in the region of $400-4000 \mathrm{~cm}^{-1}$, and (c) SBA-15-FA sample in the region of $1400-1700 \mathrm{~cm}^{-1}$, respectively.

\subsection{Catalytic Pyrolysis of Sacha Inchi Residues}

\subsubsection{Non-Catalytic Pyrolysis}

The non-catalytic pyrolytic products of the SI residues pyrolyzed at $400-600{ }^{\circ} \mathrm{C}$ could be classified into nine organic compounds, including aliphatic hydrocarbons, aromatic hydrocarbons, carboxylic acids, ketones, aldehydes, alcohols, esters, ethers, and N-containing compounds, as shown in Figures 7 and 8. The major compounds derived from the SI residues that appeared at a retention time (RT) between 2 and 10 min under a thermal condition were light aliphatic and aromatic hydrocarbons, while the heavier compounds, including the oxygenated compounds (carboxylic acids, alcohols, ketones, esters, etc.), heavy aliphatic hydrocarbons, and N-compounds were found in the middle (at RT 10-30 $\mathrm{min}$ ) and at the end of the chromatogram (at RT 30-50 min). The carboxylic acid with the highest peak at a retention time between 37 and $38 \mathrm{~min}$ can be represented as the main compound, which was mostly linoleic acid (C18:2), and it was generally found in the oil fraction of sacha inchi $(32-45 \%)[25,26]$. The main unsaturated fatty acid (C18:2) was chiefly derived as a result of the decomposition of triglycerides by $\beta$-elimination reaction [27]. When the temperature increased, acid compounds increased from $38.5 \%$ at $400{ }^{\circ} \mathrm{C}$ to $42.6 \%$ at $500{ }^{\circ} \mathrm{C}$, and then, they significantly 
decreased to $29.6 \%$ at $600{ }^{\circ} \mathrm{C}$. The unsaturated fatty acid decreased at high temperatures as a result of deoxygenation (hydrodeoxygenation, decarboxylation, decarbonylation) and breakdown of the $\mathrm{C}-\mathrm{C}$ bond though $\beta$-scission reactions, producing light hydrocarbons, $\mathrm{CO}, \mathrm{CO}_{2}$, and $\mathrm{H}_{2} \mathrm{O}$. Consequently, hydrocarbons, particularly cyclic compounds, can be formed by means of two reaction routes, namely, the Diels-Alder reaction and intermolecular radical cyclization, in order to generate $C_{5}-C_{6}$ cycloalkanes and cycloalkenes, as well as aromatic hydrocarbon compounds [27-29]. As a result, a high content of aliphatic compounds can be observed at a high pyrolysis temperature up to $43 \%$. It is well-known that hydrocarbon compounds can improve the heating value of bio-oil.

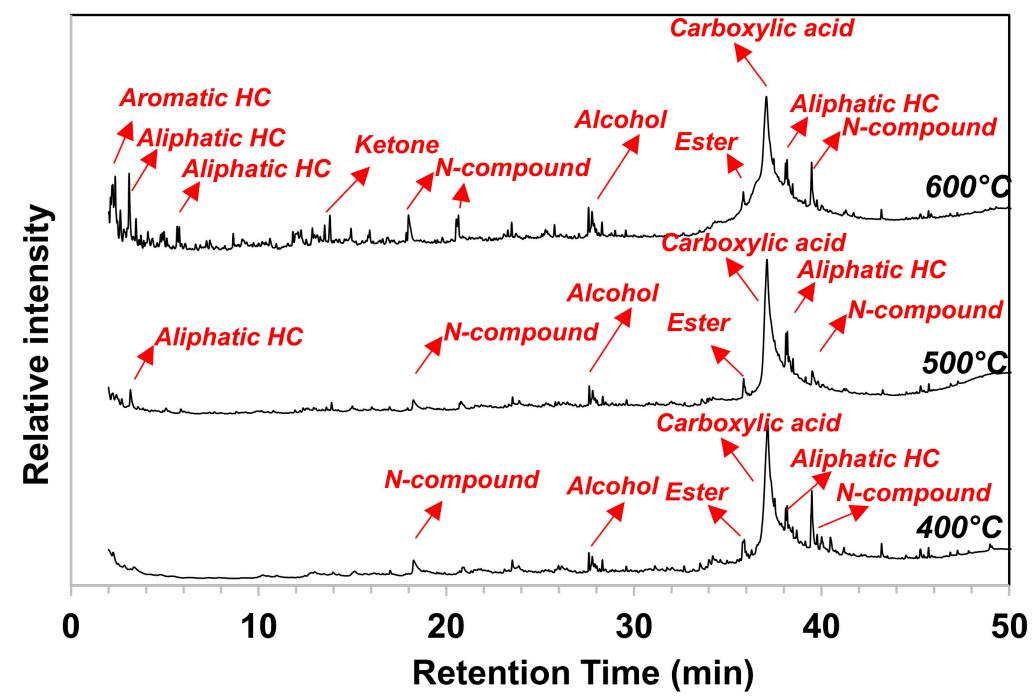

Figure 7. Pyrolysis-GC/MS (Py-GC/MS) chromatograms of Sacha inchi (SI) pyrolyzed products at pyrolysis temperature of $400-600{ }^{\circ} \mathrm{C}$.

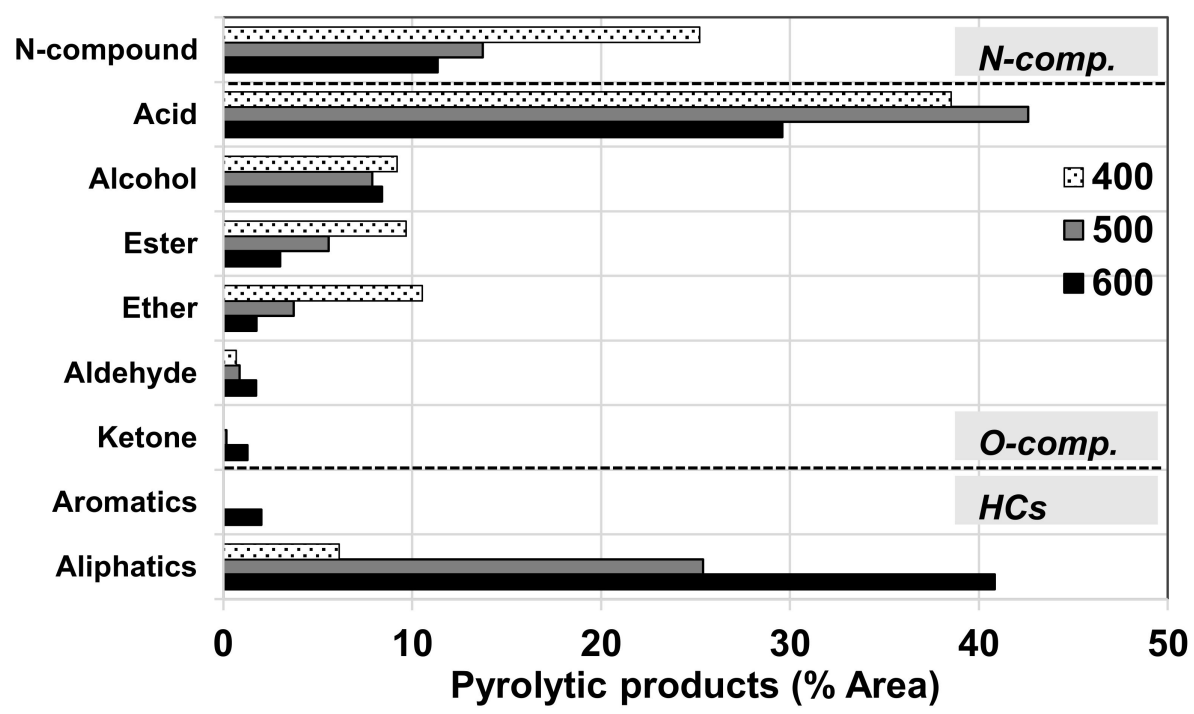

Figure 8. The non-catalytic product selectivity (\% area) detected from GC/MS of SI residues pyrolyzed at $400-600{ }^{\circ} \mathrm{C}$.

A low concentration of ketones and aldehydes were detected $(<2 \%)$, while the fractions of esters, ethers, and alcohols were found to be small in quantity at $3.0-9.7 \%, 1.8-10.5 \%$, and $7.9-9.2 \%$, respectively. These oxygenated compounds lead to the poor quality of bio-oil in terms of lowering heating values and decreasing its stability. Furthermore, the high content of $\mathrm{N}$-containing compounds, which mainly consist of amides, nitriles, and indoles, were found to be remarkable at $11.4-25.2 \%$ 
depending on the pyrolysis temperature. The high level of $\mathrm{N}$-containing compounds may cause environmental issues as a result of NOx emissions during the combustion process [8,24]. From the non-catalytic results, the large fractions of undesirable compounds were significantly obtained at $45.8-68.6 \%$ for the oxygenated compounds and at $11.4-25.2 \%$ for $\mathrm{N}$-compounds.

The pyrolysis temperature played an important role in the non-catalytic compositions. Although the highest selectivity of aliphatic hydrocarbons could be obtained at $600{ }^{\circ} \mathrm{C}$, the maximum liquid yield was not achieved under that pyrolysis temperature. According to previous studies, the highest yield of bio-oil was achieved at a moderate pyrolysis temperature $\left(\sim 500^{\circ} \mathrm{C}\right)$. Rising pyrolysis temperature $\left(600-700^{\circ} \mathrm{C}\right)$ further promoted the secondary cracking reactions of organic vapors, leading to an increase in gas proportion [30,31]. Thus, a temperature of $500^{\circ} \mathrm{C}$ was selected as the pyrolysis temperature for evaluating the catalytic performance of the fly ash-derived SBA- 15.

\subsubsection{Effect of Biomass: Catalyst Weight Ratio}

The catalytic evaluation of the fly ash-derived SBA-15 for deoxygenating pyrolysis vapors from the pyrolysis of the SI residues was investigated using Py-GC/MS. Moreover, the effect of the SI residues to SBA-15 ratio (SI/SBA-15 ratios of 1:1, 1:5, and 1:10) on pyrolytic products was studied. Furthermore, SBA-15 synthesized from chemicals and commercial SBA-15 catalysts were also investigated for comparison.

The catalytic cracking mechanism of oil plants can be explained by Sinh et al. and Vichaphund et al. [24,32]. Initially, the thermal cracking of heavier oxygenated species such as long-chain fatty acids, which are the main components of vegetable oils, can take place both on the external surface and in the internal pore of zeolites to obtain smaller oxygenated compounds and hydrocarbons. Then, the oxygenated species undergo deoxygenation reactions (decarboxylation, decarbonylation, and dehydration) for the removal of oxygen in the form of $\mathrm{CO}_{2}, \mathrm{CO}$, and $\mathrm{H}_{2} \mathrm{O}$, consequently resulting in the formation of hydrocarbons. These active hydrocarbons can be broken down into lighter hydrocarbon chains, including olefins and paraffin. In addition, this hydrocarbon with a lower molecular weight can be activated by the active site of the zeolite structure to undergo further isomerization, cyclization, and aromatization to form cyclic hydrocarbons and aromatic hydrocarbons, which is within the gasoline and diesel ranges.

In this catalytic run, the incorporation of mesoporous SBA-15 catalysts, which had been synthesized from fly ash, chemical reagent, and commercial SBA-15, enhanced the degree of deoxygenation reactions, and consequently, the quality of bio-oil improved. As shown in Figure 9, the presence of SBA-15 catalysts remarkably decreased the level of fatty acid compounds, while the fraction of aliphatic hydrocarbons significantly increased.

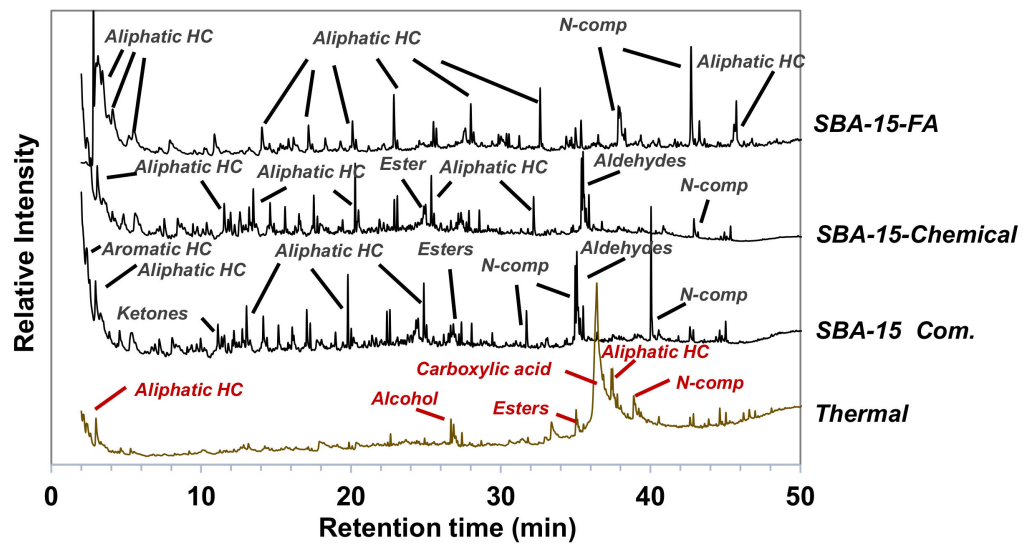

Figure 9. Py-GC/MS chromatograms of SI pyrolysis products over SBA- 15 catalysts at $500{ }^{\circ} \mathrm{C}$ with a SI/SBA-15 ratio of 1:5. 
At low catalyst content and a SI/SBA-15 ratio of 1:1 (Figure 10), SBA-15 catalysts remarkably decreased the level of carboxylic acid compounds through decarboxylation, decarbonylation, and cracking reactions due to the acidity of SBA-15 catalysts [2,33]. As a result, the formation of aliphatic hydrocarbons largely increased from $25.8 \%$ (no catalyst) to $68.9 \%$ for SBA-15-FA, $53.7 \%$ for SBA-15-chemical, and $42.2 \%$ for SBA-15-commercial. This result corresponded with the findings of a previous report that studied the catalytic conversion of waste cooking oil (WCO) (mainly palmitic $\left(\mathrm{C}_{16}\right)$ and linoleic fatty acid $\left(\mathrm{C}_{18}\right)$ ) for biofuel production using MeO-SBA-15. The proportion of fatty acid in WCO decreased when MeO-SBA-15 catalysts were used, as these mesoporous catalysts promote the formation of hydrocarbon through decarbonylation, cracking, and decarboxylation [2]. The ability of SBA-15 catalyst to produce aliphatic hydrocarbons was reported by Ozbay et al., who investigated the catalytic pyrolysis of banana peel waste using Al-modified SBA-15 and found that the compositions of the bio-oil catalyzed using Al-SBA-15 materials $(15 \mathrm{wt} \%)$ contained a high aliphatic fraction up to $55.1 \%$, while a lower fraction of aromatics at $25.1 \%$ was achieved [34]. This may be due to the larger pore characteristics of SBA-15, which facilitate the production of linear/cyclic hydrocarbons. However, SBA-15 catalysts did not reduce the proportion of other oxygenated compounds, including ketones, aldehydes, esters, and alcohols at this ratio. However, $\mathrm{N}$-compounds were still found to be in the range of $12.3-14.5 \%$. Compared to the SBA-15 synthesized from chemicals and commercials, SBA-15-FA showed better results in terms of encouraging the deoxygenation of oxygenated compounds and enhancing the production of aliphatic hydrocarbons.

When the catalyst was increased by five times (SI:SBA-15 ratio of 1:5), a higher amount of SBA-15 catalysts significantly improved the pyrolytic vapors and their selectivity compared to a lower amount of catalyst (SI:SBA-15 ratio of 1:1). The acid compounds were eliminated during the decarboxylation reaction, whereas the other oxygenated compounds slightly decreased. SBA-15-FA was more effective in reducing the oxygenated compounds $(6.9 \%)$ with no significant change in the $\mathrm{N}$-compounds (13.2\%). As a result, SBA-15-FA promoted a higher formation of aliphatic hydrocarbons compared to the others. The production of more aliphatic compounds over SBA-15-FA, compared to those over SBA-15-chemical and SBA-15-commercial, suggested that the presence of Al embedded in the SBA-15-FA framework contributed to the increase in acidity, thus promoting cracking reactions, deoxygenation (e.g., decarboxylation, decarbonylation), and isomerization [31].

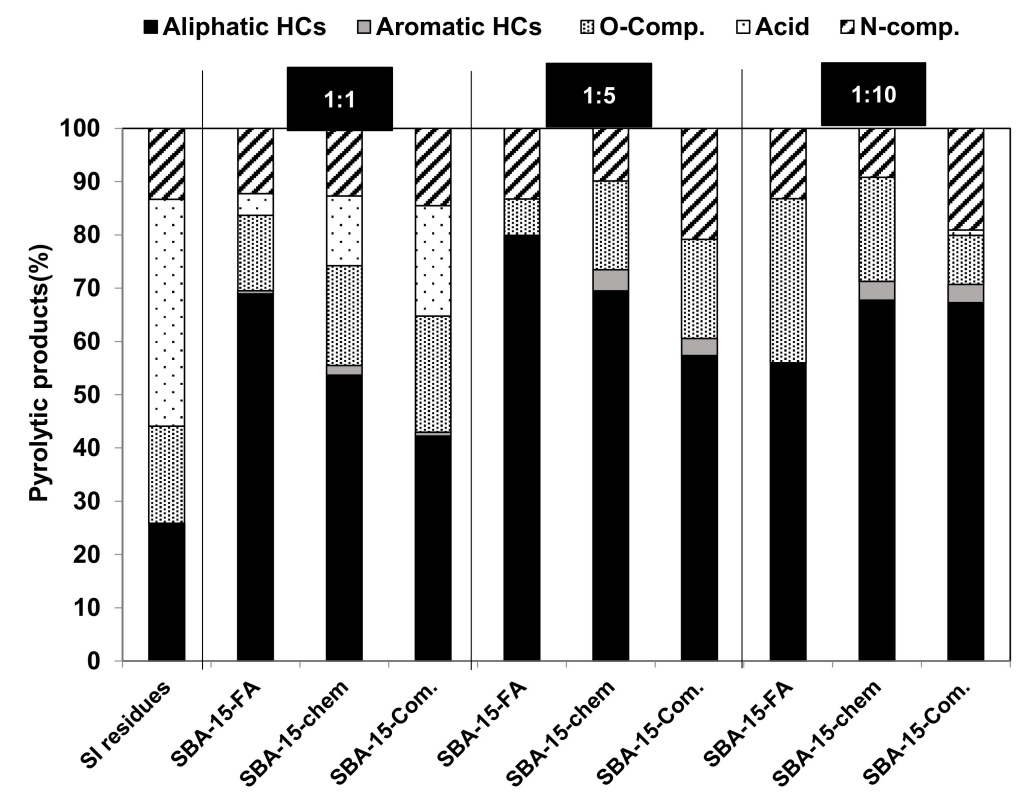

Figure 10. The pyrolytic products (\% area) obtained from Py-GC/MS of Sacha inchi residues using SBA-15 catalysts synthesized from fly ash, chemical reagents, and commercials with SI/SBA-15 ratios of $1: 0,1: 1,1: 5$, and $1: 10$, respectively. 
Furthermore, the effect of well-ordered mesoporous silica with a large pore size is particularly crucial, as their large pore size can cause the bulky molecules to react at the active site inside the zeolite framework, leading to greater hydrocarbon yields. Kamaruzaman et al. found that the lowest hydrocarbon yield was obtained when Co/SBA- 15 was used, which had the smallest pore size $(5.40 \mathrm{~nm})$ [35]. A similar trend was found in this work; SBA-15-commercial with the smallest pore size $(5.81 \mathrm{~nm})$ produced the lowest amount of hydrocarbons, compared to SBA-15-FA and SBA-15-chemical, with pore sizes of $7.42 \mathrm{~nm}$ and $6.27 \mathrm{~nm}$, respectively.

Thus, the aliphatic selectivity was in the following order: SBA-15-FA $(79.9 \%)>$ SBA-15-chemical $(69.5 \%)>$ SBA-15-commercial $(57.3 \%)$. However, the mesoporous SBA-15 catalysts showed a relatively low aromatic selectivity at $0-4.0 \%$. This is probably due to their mesopore characteristics and low amount of acidity limiting the aromatic formation. The mesopore of SBA-15 catalysts played a dominating role in the mass transfer and diffusion of large molecules into pores along with a variety of reactions including cracking, deoxygenation, isomerization, and cyclization for aliphatic hydrocarbon production. In terms of aromatization reaction, Rahman et al. suggested that the production of aromatic hydrocarbons was closely related to the accessible $\operatorname{Br} \varphi$ nsted acid sites within the framework of the zeolite catalyst [35]. Unfortunately, from our studies, the pyridine-FTIR showed that there was a small peak associated with $\operatorname{Br} \varphi$ nsted acid sites of SBA-15-FA, which had the Si/Al of 144.9. Thus, the high $\mathrm{Si} / \mathrm{Al}$ ratio of this catalyst decreased the aromatic selectivity. This was in agreement with Jeon et al. [9], who used the mesoporous SBA-15-based materials (SBA-15, Al/SBA-15, (Pd, Pt)/SBA-15) in the catalytic pyrolysis of commercial cellulose and hemicellulose (xylan) and reported that a low aromatic yield (less than 5\% area) was obtained when SBA-15 and Al/SBA-15 catalysts were used. The acidity limitation of Al/SBA-15 catalyst was reported by Qiang et al., who studied the catalytic fast pyrolysis of sawdust using SBA-15 and Al/SBA-15 with different Si/Al ratios (10-70). They suggested that the production of aromatic hydrocarbon including mainly toluene was detected in a small content $(\leq 0.4 \%)$ when using $\mathrm{Al} / \mathrm{SBA}-15$ with the $\mathrm{Si} / \mathrm{Al}$ of $10-70$. The lowest yield was approximately $0.3 \%$ when using $\mathrm{Al} / \mathrm{SBA}-15$ with the highest $\mathrm{Si} / \mathrm{Al}$ ratio of 70 , which reduced the concentration of acid sites due to the lowest $\mathrm{Al}$ atoms in the structure and consequently, it decreased the catalytic activity [11].

At the highest catalyst loading (SI:SBA-15 ratio of 1:10), the degree of aliphatic conversion tended to significantly decrease for the highest catalyst content, which might be attributed to catalyst deactivation. Coke formation occurred due to the re-polymerization of deoxygenated intermediates and the condensation of hydrocarbons [35]. The relative amount (wt \%) of coke deposited on spent SBA- 15 catalysts after pyrolysis is shown in Table 3. It can be seen that the amount of catalyst had an effect on the coke formation. Increasing the catalyst content resulted in an increase in coke formation on the surface of SBA- 15 catalysts. Using SBA-15 derived from fly ash (SBA-15-FA) exhibited relatively higher coke deposited when compared with other catalysts at the SI:SBA-15 ratio of 1:10. The coke formation of synthesized SBA-15 catalysts corresponded to the decrease in the aliphatic hydrocarbon, as mentioned earlier. Consequently, undesirable products were observed in a high amount at 9.2-30.9\% for the oxygenated compounds and $9.2-19.1 \%$ for the $\mathrm{N}$-compounds.

Table 3. Relative amount (wt \%) of coke deposited on spent SBA-15 catalysts.

\begin{tabular}{ccc}
\hline SI:SBA-15 Ratio & Catalysts & Coke (\%) \\
\hline \multirow{2}{*}{$1: 5$} & SBA-15-FA & 6.10 \\
& SBA-15-chem & 5.38 \\
& SBA-15-com & 6.17 \\
\hline \multirow{2}{*}{$1: 10$} & SBA-15-FA & 9.27 \\
& SBA-15-chem & 7.27 \\
& SBA-15-com & 8.33 \\
\hline
\end{tabular}

From these results, it can be concluded that SBA-15 derived from fly ash (SBA-15-FA) showed a high efficiency that improves the hydrocarbon selectivity up to $80 \%$ at a SI:SBA-15 ratio of 1:5 with 
the ability to decrease the oxygenated compounds to $6.9 \%$. Interestingly, SBA-15 derived from fly ash exhibited superior catalytic performance in terms of producing hydrocarbon compounds $(80 \%)$ compared to the commercial SBA-15 (61\%). Therefore, SBA-15 derived from fly ash (SBA-15-FA) can be used as an acid catalyst for a catalytic biomass pyrolysis application.

\subsubsection{Hydrocarbon Distribution and Selectivity}

During the catalytic process, the aliphatic hydrocarbons were the main compositions, which consisted of linear hydrocarbons (e.g., alkanes, alkenes, alkynes) and cyclic hydrocarbons (cycloalkanes and cycloalkenes), with a small number of aromatic hydrocarbons (monocyclic aromatic HC: MAHs). The main compounds obtained due to non-catalytic pyrolysis were alkanes $(4.9 \%)$, alkenes $(7.3 \%)$, cycloalkanes $(8.4 \%)$, and cycloalkenes (4.3\%), as shown in Figure 11.

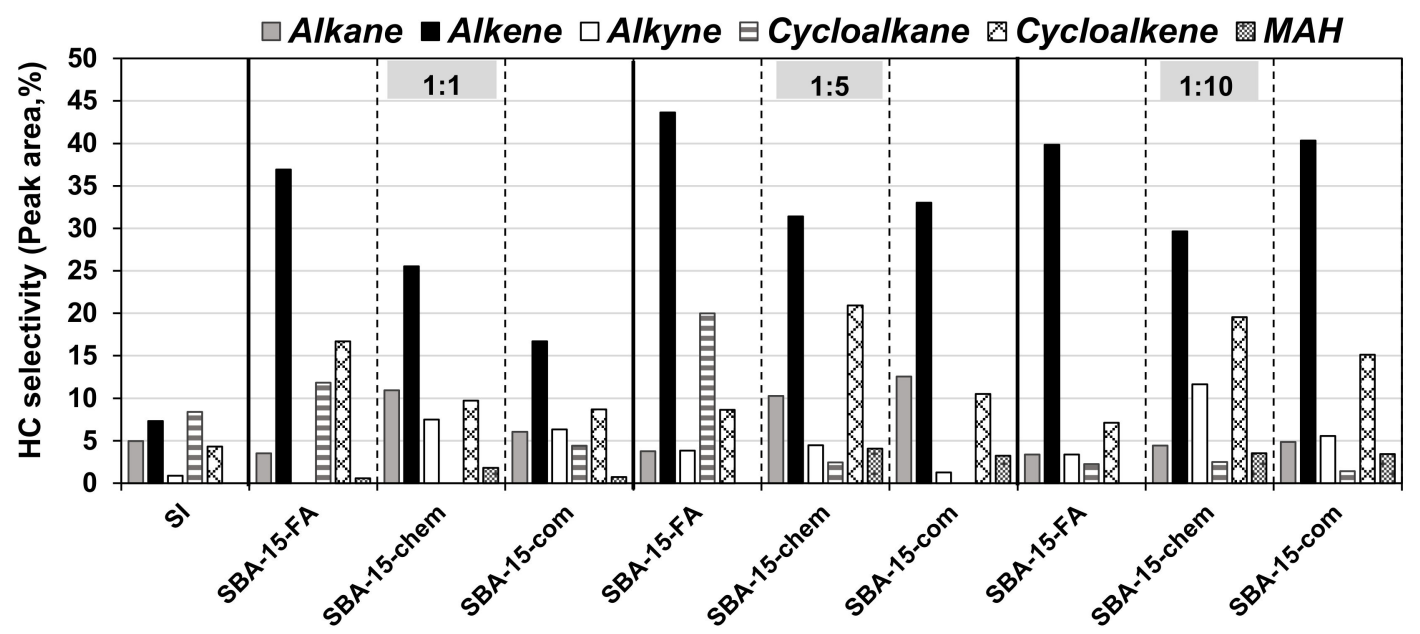

Figure 11. Hydrocarbon distribution of thermal and catalytic pyrolysis of the SI residues using SBA-15 catalysts.

The formation of cycloalkanes (mainly cyclohexanes $\left(\mathrm{C}_{6}\right)$ ) and cycloalkenes (e.g., cyclopentenes $\left(C_{5}\right)$, cyclohexenes $\left(C_{6}\right)$, and cycloheptenes $\left(C_{7}\right)$ ) can be formed by means of two reaction pathways, including the Diels-Alder reaction and intermolecular cyclization. The incorporation of SBA-15 catalysts significantly increased the selectivity of aliphatic hydrocarbon at SI:SBA-15 ratios of 1:1 and 1:5. In the case of linear hydrocarbon, the formation of alkenes was preferred over that of alkanes and alkynes, confirming that the decarbonylation was the dominant deoxygenation pathway $[28,36]$. Meanwhile, cycloalkanes and cycloalkenes were found to be the minor constituents. Moreover, it could be seen that there was a production of small amounts of monocyclic aromatic hydrocarbons such as toluene and ethylbenzenes (0.6-4.0\%) when SBA-15 catalysts were used. Aromatic compounds such as monocyclic aromatic hydrocarbons can be formed through the dehydrogenation of cyclohexenes [28].

Additionally, these hydrocarbons can be classified into three groups according to the carbon lengths of ranges $C_{5}-C_{12}, C_{13}-C_{20}$, and $C_{>20}$, as shown in Figure 12. From this result, the predominant carbon lengths produced from SBA-15 catalysts were $C_{5}-C_{12}$ and $C_{13}-C_{20}$, which were within the ranges of gasoline and diesel, respectively. SBA-15-FA at a high catalyst content (at a SI:SBA-15 ratio of 1:5) offered higher proportions of $C_{5}-C_{12}$ and $C_{13}-C_{20}$, indicating that SBA- 15 derived from fly ash can be utilized as a catalyst in the pyrolysis of oilseed residues for hydrocarbon conversion and consequently improve the quality of bio-oil. 


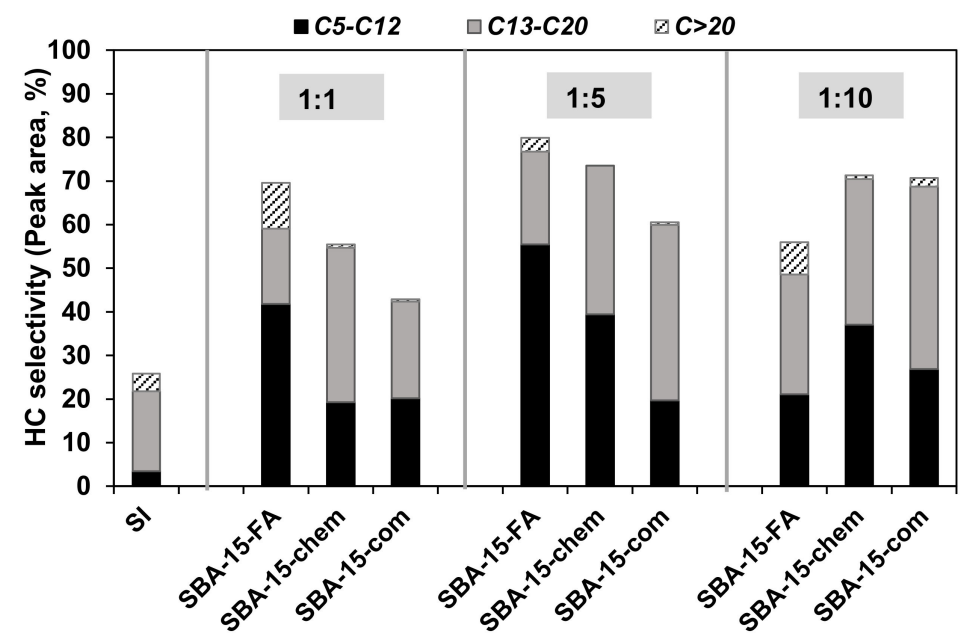

Figure 12. Hydrocarbon selectivity of the pyrolytic products from the SI residues with SBA-15 catalysts.

\section{Materials and Methods}

\subsection{Sacha Inchi (SI) Residues}

The SI residues obtained from oil extraction plants in the Kamphaeng Phet province, Thailand were used as a biomass feedstock in the pyrolysis experiment (Figure 13). Before the experiment, the SI residues were dried, ground, and sieved to achieve a particle size of $125-425 \mu \mathrm{m}$. The proximate and elemental analyses of SI residues have been presented in Table 4 . The results of the proximate analysis showed the presence of $71.63 \%$ volatile matter, $14.58 \%$ fixed carbon, $5.63 \%$ moisture content, and an ash content of $8.16 \%$. The elemental result revealed that the SI residues consisted of C:41.96\%, H:6.97\%, $\mathrm{N}: 1.76 \%$, and $\mathrm{O}: 49.31 \mathrm{wt} \%$. Based on this elemental composition, the approximate normalized formula of the SI residues can be written as $\left(\mathrm{C}_{3.5} \mathrm{H}_{7.0} \mathrm{O}_{3.1} \mathrm{~N}_{0.1}\right)$ n. In addition, the heating value of the SI residues was quite high at $24.9 \mathrm{MJ} / \mathrm{kg}$, compared to other biomass residues.

(a)

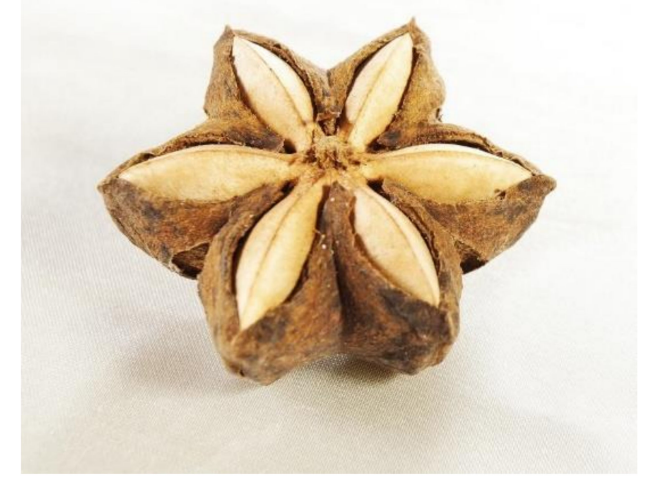

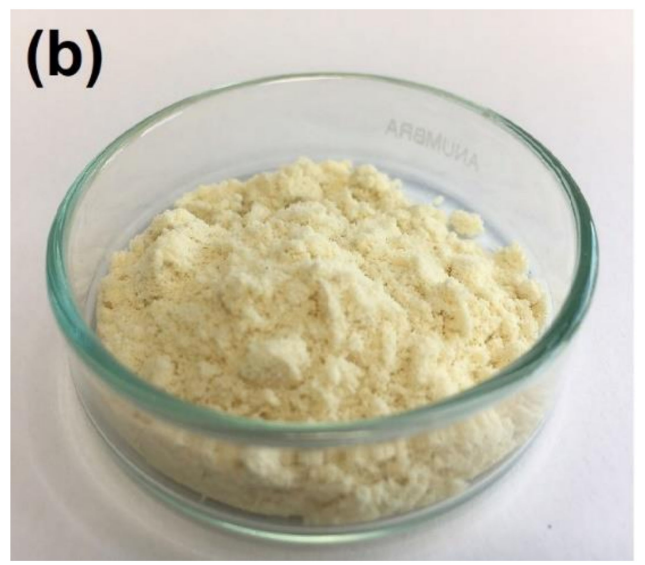

Figure 13. The physical appearance of (a) Sacha inchi seed and (b) the SI residues obtained after the oil extraction process. 
Table 4. Elemental and proximate analyses of SI residues.

\begin{tabular}{cc}
\hline Analysis & SI Residues \\
\hline Element, wt \% & \\
Carbon & 41.96 \\
Hydrogen & 6.97 \\
Nitrogen & 1.76 \\
Oxygen * & 49.31 \\
Proximate, wt $\%$ & \\
Volatiles & 71.63 \\
Fixed carbon & 14.58 \\
Ash & 8.16 \\
Moisture & 5.63 \\
High heating value $(\mathrm{HHV}, \mathrm{MJ} / \mathrm{kg})$ & 24.9 \\
\hline
\end{tabular}

\subsection{Synthesis $S B A-15$ Catalysts}

\subsubsection{SBA-15 from the Chemical Reagent}

The mesoporous silica SBA-15 was synthesized using the hydrothermal method. The initial molar gel composition was $1 \mathrm{SiO}_{2}$ : $0.017 \mathrm{P}_{123}: 1.35 \mathrm{HCl}: 19.77 \mathrm{H}_{2} \mathrm{O}$. For each batch, $4.26 \mathrm{~g}$ of Pluronic P123 (EO20PO70EO20; $\mathrm{MWav}=5800$, Aldrich) was dissolved into a $2 \mathrm{M} \mathrm{HCl}$ solution and deionized water (D.I. water) and stirred at $40^{\circ} \mathrm{C}$ for $1 \mathrm{~h}$. After the complete dissolution of P123, tetraethyl orthosilicate ( $8.5 \mathrm{~g}$ of TEOS, $98 \%$, Sigma-Aldrich) was added to the mixture solution, which was continuously stirred at $40^{\circ} \mathrm{C}$ for $20 \mathrm{~h}$. After this homogenous mixing process, the milky solution obtained was transferred to a Teflon-lined autoclave at $100^{\circ} \mathrm{C}$ for $24 \mathrm{~h}$ for crystallization. The white solid powder was filtered, washed, and dried overnight at $100{ }^{\circ} \mathrm{C}$. Following this, the dry solid sample was calcined at $550{ }^{\circ} \mathrm{C}$ for $6 \mathrm{~h}$ in the air atmosphere.

\subsection{SBA-15 Derived from Coal Fly Ash}

\section{Acid Treatment of Fly Ash}

The CFA, which was used as a raw material in this experiment, was obtained from the Mae Moh electric power generation plant in Lampang, Thailand. Its chemical composition determined by XRF is given in Table 5. Due to high amounts of impurities, such as $\mathrm{CaO}$ and $\mathrm{Fe}_{2} \mathrm{O}_{3}$, in the CFA, the acid treatment was initially executed before the SBA-15 synthesis to improve the purity of the synthesized zeolite $[24,37]$. This acid treatment procedure was adapted from $[24,38]$. Then, $10 \mathrm{~g}$ of CFA was mixed with $100 \mathrm{~mL}$ of $1 \mathrm{M} \mathrm{HCl}$ and stirred at $90^{\circ} \mathrm{C}$ for $1 \mathrm{~h}$ to remove the impurities. Following this, the treated powder was washed with deionized water, filtered, and dried at $100^{\circ} \mathrm{C}$ for $24 \mathrm{~h}$.

Table 5. Chemical compositions of fly-ash determined by X-Ray Fluorescence (XRF).

\begin{tabular}{cccccccccccc}
\hline $\mathrm{SiO}_{2}$ & $\mathrm{Al}_{2} \mathrm{O}_{3}$ & $\mathrm{CaO}$ & $\mathrm{Fe}_{2} \mathrm{O}_{3}$ & $\mathrm{SO}_{3}$ & $\mathrm{~K}_{\mathbf{2}} \mathrm{O}$ & $\mathbf{M g O}$ & $\mathrm{Na}_{2} \mathrm{O}$ & $\mathrm{TiO}_{2}$ & $\mathbf{P}_{\mathbf{2}} \mathrm{O}_{5}$ & $\mathbf{M n O}$ & $\mathrm{ZrO}_{2}$ \\
\hline$(\%)$ & $(\%)$ & $(\%)$ & $(\%)$ & $(\%)$ & $(\%)$ & $(\%)$ & $(\%)$ & $(\%)$ & $(\%)$ & $(\%)$ & $(\%)$ \\
28.55 & 16.06 & 23.4 & 17.03 & 7.37 & 2.17 & 2.44 & 1.72 & 0.48 & 0.25 & 0.14 & 0.03 \\
\hline
\end{tabular}

SBA-15 Synthesis from Fly Ash via Alkali Fusion Followed by Hydrothermal Treatment.

After the acid treatment, alkaline fusion and silicate extraction of the treated fly ash were conducted following the method suggested in the literature by Kumar et al. [16]. The treated fly ash was homogenously mixed with sodium hydroxide $(\mathrm{NaOH})$ at a ratio of 1:1.2 in terms of weight. Subsequently, the solid mixture was heated in a muffle furnace at $550{ }^{\circ} \mathrm{C}$ for $1 \mathrm{~h}$. After the heat treatment, the fused fly ash was mixed with deionized water at a weight ratio of 1:4 and stirred at 
room temperature for $24 \mathrm{~h}$. Lastly, the turbid suspension was centrifuged and filtered to achieve the supernatant solution. The initial molar gel composition for synthesizing SBA-15-FA was $1 \mathrm{SiO}_{2}$ : $0.057 \mathrm{Al}_{2} \mathrm{O}_{3}: 0.025 \mathrm{P}_{123}: 2.77 \mathrm{HCl}: 65.04 \mathrm{H}_{2} \mathrm{O}$. For each experiment, $4.48 \mathrm{~g}$ of $\mathrm{P} 123$ was dissolved into a $37 \mathrm{wt} \% \mathrm{HCl}$ solution and D.I. water and then stirred at $40{ }^{\circ} \mathrm{C}$ for $1 \mathrm{~h}$. Tetraethyl orthosilicate (TEOS) with the $\mathrm{SiO}_{2}$ proportion of 0.77 and the supernatant extracted from fly ash with the $\mathrm{SiO}_{2}$ proportion of 0.23 were added to the above P123 solution. Following this, the mixed solution was continuously stirred until a milky gel formation could be seen. Subsequently, this milky solution was stirred at $40^{\circ} \mathrm{C}$ for $20 \mathrm{~h}$, after which it was transferred to a Teflon-lined autoclave for the hydrothermal treatment at $100{ }^{\circ} \mathrm{C}$ for $72 \mathrm{~h}$. Afterward, the solid product was filtered, washed, and dried overnight at $100{ }^{\circ} \mathrm{C}$. Finally, the dry solid sample was calcined at $550^{\circ} \mathrm{C}$ for $6 \mathrm{~h}$ in an air atmosphere to obtain SBA-15 derived from CFA (SBA-15-FA).

\subsection{Raw Material and Catalyst Characterizations}

The chemical compositions of fly ash and synthesized SBA-15-FA sample were characterized by X-Ray Fluorescence (XRF: Philips PW 2404) and Micro Energy Dispersive X-ray Fluorescence Spectrometer ( $\mu$-EDXRF; Orbis PC; EDAX (AMETEK)) equipped with a rhodium X-ray source ( $30 \mathrm{kV}$, $1000 \mu \mathrm{A}$ ) and with a silicon drift detector. The crystal structure of SBA-15 zeolite was investigated using an X-ray diffractometer (Rigaku TTRAX III) equipped with a CuK $\alpha$ source at $50 \mathrm{kV}$ and $300 \mathrm{~mA}$. The scan range of the small angle was at $2 \theta=0.5-5^{\circ}$ at a scan rate of $1{ }^{\circ} \mathrm{C} / \mathrm{min}$. The morphology of SBA-15 zeolite was determined with the help of a scanning electron microscope (SEM) (Hitachi, SU 5000). The mesoporous SBA-15 was observed through transmission electron microscopy (TEM) images using a JEOL, JEM-2100Plus operated at $200 \mathrm{kV}$. The surface area, the total pore volume, and the pore size were determined by nitrogen adsorption-desorption isotherms at $77 \mathrm{~K}$ in Quantachrome's Autosorb-1 analyzer. The surface area was calculated using the Brunauer-Emmett-Teller (BET) equation, while the total pore volume was measured at P/P0 0.99. Prior to the BET, the surface area measurement samples were heated at $300{ }^{\circ} \mathrm{C}$ in vacuum for $8 \mathrm{~h}$. The acidity of the synthesized SBA-15 catalysts was determined by ammonia temperature-programmed desorption $\left(\mathrm{NH}_{3}\right.$-TPD) with the help of a BELCAT instrument. The catalyst $(0.3 \mathrm{~g})$ was pre-treated at $500{ }^{\circ} \mathrm{C}$ for $1 \mathrm{~h}$ under a helium (He) atmosphere. After cooling it to $100{ }^{\circ} \mathrm{C}, \mathrm{NH}_{3}$ gas adsorption was conducted for $1 \mathrm{~h}$ and consequently purged with $\mathrm{He}$ at ambient temperature for $30 \mathrm{~min}$. Next, the SBA-15 sample was heated up to $600{ }^{\circ} \mathrm{C}$ under He flow with a ramping rate of $20^{\circ} \mathrm{C} / \mathrm{min}$. The desorbed ammonia was identified using the thermal conductivity detector. The acidity characteristics of SBA-15 samples were determined by pyridine adsorption using a FTIR spectrometer (PerkinElmer, Spectrum Spotlight 300, FTIR). The samples $(1.5 \mathrm{mg})$ were pressed to form a pellet with $\mathrm{KBr}(100 \mathrm{mg})$. Pyridine adsorption was carried out by dropping a small amount of pyridine to the samples and then adsorption at $40^{\circ} \mathrm{C}$ for $30 \mathrm{~min}$. After adsorption, the samples were consequently evacuated at $150^{\circ} \mathrm{C}$ for $1 \mathrm{~h}$ in the oven to characterize the acid properties of catalysts $[22,23]$

\subsection{Catalyst Activity (Pyrolyzer-GC/MS System)}

The catalytic activity of SBA-15 catalysts was performed using a single-shot micro furnace pyrolyzer (Frontier Laboratories, Cabanatuan, Philippines; PY-2020iD) equipped with an auto-shot sampler (Frontier Laboratories, Cabanatuan, Philippines; AS-1020E). The pyrolysis unit was connected to a gas chromatograph (Agilent Technologies, Santa Clara, CA, USA; GC, 6890N GC) and a mass spectrometry detector (Agilent Technologies, Santa Clara, CA, USA; 5975C MSD). For a non-catalytic run, approximately $0.4 \mathrm{mg}$ of SI residues were used in an $80-\mu \mathrm{L}$ stainless steel crucible, which was then covered with a quartz wool. In order to investigate the effect of the catalyst contents, catalysts (SBA-15-FA, SBA-15-chemical, and SBA-15-commercial) were placed above the biomass layer at the SI residues to SBA-15 ratios of 1:1, 1:5, and 1:10, respectively. The pyrolysis temperature was set at $500{ }^{\circ} \mathrm{C}$. In order to initiate the experiment, the sample crucible was dropped into the heated reactor at the set temperature under He atmosphere $\left(1 \mathrm{~cm}^{3} / \mathrm{min}\right)$. The sample was rapidly pyrolyzed and 
held for $30 \mathrm{~s}$. The evolved pyrolysis vapors were automatically injected through an Ultra Alloy-5 (UA-5; $30 \mathrm{~m} \times 0.25 \mathrm{~mm}$ and $0.25 \mu \mathrm{m}$ of film thickness) capillary column into separate gas species. The column temperature profile entailed heating at $50^{\circ} \mathrm{C}$ for $3 \mathrm{~min}$, then raising the temperature to $200{ }^{\circ} \mathrm{C}$ at $5{ }^{\circ} \mathrm{C} / \mathrm{min}$ and finally to $350{ }^{\circ} \mathrm{C}$ at $10{ }^{\circ} \mathrm{C} / \mathrm{min}$. The column flow and total flow were found to be 1.30 and $69.2 \mathrm{~mL} / \mathrm{min}$, respectively. The chemical speciation of gas products was performed using mass spectrometry that is based on mass to charge ratios $(\mathrm{m} / \mathrm{z})$ of $20-800$, and the products were identified through a comparison with the National Institute of Standards and Technology (NIST) mass spectra database. Besides SBA-15-FA, the mesoporous SBA-15-synthesized chemicals and commercial SBA-15 catalysts were also utilized for comparison.

The direct quantitative analysis of condensable products of biomass pyrolysis could not feasibly be extracted from Py-GC/MS data due to complexity of products obtained from the process. It is not generally practical to make the direct quantification of these compounds via a traditional calibrated peak area procedure. Many studies rely on comparison among corresponding peak areas of these compounds to express the selectivity of particular products. In this work, product selectivity is based on percentages of relative peak area of each compound to the total peak areas obtained from the chromatogram as shown in Equation (1) [24]. In this study, the GC set-up did not allow for the separation and quantification of the light gases (e.g., $\mathrm{H}_{2}, \mathrm{H}_{2} \mathrm{O}, \mathrm{CH}_{4}, \mathrm{CO}, \mathrm{CO}_{2}, \mathrm{C}_{2}, \mathrm{C}_{3}$ ) [39]. For each catalyst, the Py-GC/MS experiment was conducted three times to confirm the reproducibility of pyrolysis products. The relative standard deviations were not much different; generally, they were within 15\%. Yu and coworkers (2012) investigated the catalytic fast pyrolysis of lignin extracted from a black liquor collected from a pulp mill and reported the reproducibility of aromatic selectivity, which was approximately $10 \%$ [40].

$$
\text { Product selectivity }(\%)=\frac{\text { Area of the desired product }}{\text { Total area of the products }} \times 100 \%
$$

\subsection{Coke Analysis}

The quantitative amount of coke was determined by thermogravimetric analysis (TGA) on a MettlerToledo (TGA/SDTA 851) instrument. The spent catalyst were heated from 30 to $850{ }^{\circ} \mathrm{C}$ and held for $10 \mathrm{~min}$ under air atmosphere $(60 \mathrm{~mL} / \mathrm{min})$ with heating rate $10^{\circ} \mathrm{C} / \mathrm{min}$. The mass loss of coke combustion was calculated between 250 and $850^{\circ} \mathrm{C}$ in order to avoid the mass loss of desorbed water at low temperature (approximately $100-250^{\circ} \mathrm{C}$ ) [24]. The relative amount of coke was calculated by Equation (2).

$$
\% \text { Relative coke }=\frac{m_{250^{\circ} \mathrm{C}}-m_{850^{\circ} \mathrm{C}}}{m_{250^{\circ} \mathrm{C}}} \times 100
$$

\section{Conclusions}

SBA-15 derived from fly ash was successfully synthesized via alkali fusion followed by hydrothermal treatment. The SBA-15-FA catalyst had the Si/Al ratio of 144.9 with a specific surface area and a pore volume of $705 \mathrm{~m}^{2} / \mathrm{g}$ and $1.15 \mathrm{~cm}^{3} / \mathrm{g}$, respectively, which were greater than SBA-15 synthesized from chemical reagent and commercial SBA- 15 catalyst. The incorporation of $\mathrm{Al}$ in the structure increased the pore size as well as acid strength, particularly the Lewis acid sites for the SBA-15-FA catalyst. After the catalytic pyrolysis, the carboxylic acids, which were mainly linoleic acid (C18:2), were eliminated through the decarboxylation reaction, while other oxygenated compounds decreased slightly to a SI:SBA-15 ratio of 1:5. As a result, the formation of aliphatic hydrocarbons largely increased in the following order: SBA-15-FA $(79.9 \%)>$ SBA-15-chemical $(69.5 \%)>$ SBA-15-commercial $(57.3 \%)$. However, there was only a slight change in the decrease in N-compounds $(9.2-12.9 \%)$. However, the mesoporous SBA-15 catalysts exhibited a relatively low aromatic selectivity at $0-4.0 \%$. SBA-15 derived from fly ash (SBA-15-FA) showed high efficiency in terms of improvement in the hydrocarbon selectivity up to $80 \%$, with the ability to decrease the oxygenated compounds to $6.9 \%$. 
In terms of the aliphatic compositions, the formation of alkenes was favored over that of alkanes and alkynes; on the other hand, cycloalkanes and cycloalkenes were found as the minor constituents. SBA-15-FA at a high catalyst content (SI:SBA-15 ratio of 1:5) offered higher proportions of gasoline $\left(C_{5}-C_{12}\right)$ and diesel $\left(C_{13}-C_{20}\right)$ ranges. Therefore, SBA-15 derived from fly ash was an effective catalyst in terms of improving the overall bio-oil quality through pyrolysis application.

Supplementary Materials: The following are available online at http://www.mdpi.com/2073-4344/10/9/1031/s1.

Author Contributions: Conceptualization, D.A.; methodology, C.S. and S.V.; TEM, SEM, XRD, FTIR, N2 adsorption-desorption, TPD and Py-GC/MS investigations, C.S.; TEM, SEM, XRD, FTIR, N2 adsorption-desorption, TPD and Py-GC/MS analysis, C.S. and S.V.; writing—original draft preparation, C.S. and S.V.; writing-review and editing, S.V., V.S. and D.A.; supervision, D.A.-O.; project administration, D.A.; funding acquisition, D.A. All authors have read and agreed to the published version of the manuscript.

Funding: This research was funded by the Thailand Graduate Institute of Science and Technology (TGIST, TG-33-09-59-011D) and the National Metal and Materials Technology Center, Thailand (Project No. MT-B-58-CER-07-308-I).

Conflicts of Interest: The authors declare no conflict of interest.

\section{References}

1. Anwar, M.; Rasul, M.G.; Ashwath, N.; Nabi, M.D.N. The Potential of Utilising Papaya Seed Oil and Stone Fruit Kernel Oil as Non-Edible Feedstock for Biodiesel Production in Australia-A Review. Energy Rep. 2019, 5, 280-297. [CrossRef]

2. Cao, X.; Li, L.; Shitao, Y.; Liu, S.; Hailong, Y.; Qiong, W.; Ragauskas, A.J. Catalytic Conversion of Waste Cooking Oils for the Production of Liquid Hydrocarbon Biofuels Using In-Situ Coating Metal Oxide on SBA-15 as Heterogeneous Catalyst. J. Anal. Appl. Pyrolysis 2019, 138, 137-144. [CrossRef]

3. Rawdkuen, S.; Murdayanti, D.; Ketnawa, S.; Phongthai, S. Chemical Properties and Nutritional Factors of Pressed-Cake from Tea and Sacha Inchi Seeds. Food Biosci. 2016, 15, 64-71. [CrossRef]

4. Zuleta, E.C.; Rios, L.A.; Benjumea, P.N. Oxidative Stability and Cold Flow Behavior of Palm, Sacha-Inchi, Jatropha and Castor Oil Biodiesel Blends. Fuel Process. Technol. 2012, 102, 96-101. [CrossRef]

5. Hernando, H.; Fermoso, J.; Ochoa-Hernández, C.; Opanasenko, M.; Pizarro, P.; Coronado, J.M.; Čejka, J.; Serrano, D.P. Performance of MCM-22 Zeolite for the Catalytic Fast-Pyrolysis of Acid-Washed Wheat Straw. Catal. Today 2018, 304, 30-38. [CrossRef]

6. Vichaphund, S.; Aht-Ong, D.; Sricharoenchaikul, V.; Atong, D. Effect of CV-ZSM-5, Ni-ZSM-5 and FA-ZSM-5 Catalysts for Selective Aromatic Formation from Pyrolytic Vapors of Rubber Wastes. J. Anal. Appl. Pyrolysis 2017, 124, 733-741. [CrossRef]

7. Mochizuki, T.; Chen, S.Y.; Toba, M.; Yoshimura, Y. Pyrolyzer-GC/MS System-Based Analysis of the Effects of Zeolite Catalysts on the Fast Pyrolysis of Jatropha Husk. Appl. Catal. A Gen. 2013, 456, 174-181. [CrossRef]

8. Vichaphund, S.; Sricharoenchaikul, V.; Atong, D. Utilization of Fly Ash-Derived HZSM-5: Catalytic Pyrolysis of Jatropha Wastes in a Fixed-Bed Reactor. Environ. Technol. 2017, 38, 1660-1672. [CrossRef]

9. Jeon, M.-J.; Jeon, J.-K.; Suh, D.J.; Park, S.H.; Sa, Y.J.; Joo, S.H.; Park, Y.-K. Catalytic Pyrolysis of Biomass Components over Mesoporous Catalysts Using Py-GC/MS. Catal. Today 2013, 204, 170-178. [CrossRef]

10. Zhao, D.; Feng, J.; Huo, Q.; Melosh, N.; Fredrickson, G.H.; Chmelka, B.F.; Stucky, G.D. Triblock Copolymer Syntheses of Mesoporous Silica with Periodic 50 to 300 Angstrom Pores. Science 1998, 279, 548-552. [CrossRef]

11. Qiang, L.; Wen-Zhi, L.; Dong, Z.; Xi-Feng, Z. Analytical Pyrolysis-Gas Chromatography/Mass Spectrometry (Py-GC/MS) of Sawdust with Al/SBA-15 Catalysts. J. Anal. Appl. Pyrolysis 2009, 84, 131-138. [CrossRef]

12. Kim, S.; Han, Y.; Park, J.; Park, J. Adsorption Characteristics of Mesoporous Silica SBA-15 Synthesized from Mine Tailing. Int. J. Miner. Process. 2015, 140, 88-94. [CrossRef]

13. Yang, Z.; Cai, W.; Chou, J.; Cai, Z.; Jin, W.; Chen, J.; Xiong, Z.; Ru, X.; Xia, Q. Hydrothermal Synthesis of Plugged Micro/Mesoporous Al-SBA-15 from Spent Fluid Catalytic Cracking Catalyst. Mater. Chem. Phys. 2019, 222, 227-229. [CrossRef]

14. Chong, C.C.; Abdullah, N.; Bukhari, S.N.; Ainirazali, N.; Teh, L.P.; Setiabudi, H.D. Hydrogen Production via $\mathrm{CO}_{2}$ Reforming of $\mathrm{CH} 4$ over Low-Cost Ni/SBA-15 from Silica-Rich Palm Oil Fuel Ash (POFA) Waste. Int. J. Hydrog-Energy 2019, 44, 20815-20825. [CrossRef] 
15. Chandrasekar, G.; You, K.S.; Ahn, J.W.; Ahn, W.S. Synthesis of Hexagonal and Cubic Mesoporous Silica using Power Plant Bottom Ash. Microporous Mesoporous Mater. 2008, 111, 455-462. [CrossRef]

16. Kumar, P.; Mal, N.; Oumi, Y.; Yamana, K.; Sano, T. Mesoporous Materials Prepared using Coal Fly Ash as the Silicon and Aluminum Source. J. Mater. Chem. 2001, 11, 3285-3290. [CrossRef]

17. Li, G.; Wang, B.; Sun, Q.; Xu, W.Q.; Han, Y. Adsorption of Lead Ion on Amino-Functionalized Fly-Ash-Based SBA-15 Mesoporous Molecular Sieves Prepared via a Two-Step Hydrothermal Method. Microporous Mesoporous Mater. 2017, 252, 105-115. [CrossRef]

18. Li, G.; Wang, B.; Wang, H.; Ma, J.; Xu, W.Q.; Li, Y.; Han, Y.; Sun, Q. Fe and/or Mn oxides supported on fly ash-derived SBA-15 for low-temperature NH3-SCR. Catal. Commun. 2018, 108, 82-87. [CrossRef]

19. Ściubidło, A.; Majchrzak-Kucęba, I. Exhaust Gas Purification Process using Fly Ash-Based Sorbents. Fuel 2019, 258, 116126. [CrossRef]

20. Liang, C.; Wei, M.C.; Tseng, H.H.; Shu, E.C. Synthesis and characterization of the acidic properties and pore texture of Al-SBA-15 supports for the canola oil transesterification. Chem. Eng. J. 2013, 223, 785-794. [CrossRef]

21. Qoniah, I.; Prasetyoko, D.; Bahruji, H.; Triwahyono, S.; Jalil, A.A.; Purbaningtias, T.E. Direct synthesis of mesoporous aluminosilicates from Indonesian kaolin clay without calcination. Appl. Clay Sci. 2015, 118, 290-294. [CrossRef]

22. Cheng, Y.W.; Chong, C.C.; Cheng, C.K.; Ng, K.H.; Witoon, T.; Juan, J.C. Ethylene Production from Ethanol Dehydration over Mesoporous SBA-15 Catalyst Derived from Palm Oil Clinker Waste. J. Clean. Prod. 2020, 249, 119323. [CrossRef]

23. Akti, F. Effect of kaolin on aluminum loading success in synthesis of Al-SBA-15 catalysts: Activity test in ethanol dehydration reaction. Microporous Mesoporous Mater. 2020, 294, 109894. [CrossRef]

24. Vichaphund, S.; Wimuktiwan, P.; Sricharoenchaikul, V.; Atong, D. In Situ Catalytic Pyrolysis of Jatropha Wastes using ZSM-5 from Hydrothermal Alkaline Fusion of Fly Ash. J. Anal. Appl. Pyrolysis 2019, 139, $156-166$. [CrossRef]

25. Wang, S.; Zhu, F.; Kakuda, Y. Sacha Inchi (Plukenetia volubilis L.): Nutritional Composition, Biological Activity, and Uses. Food Chem. 2018, 265, 316-328. [CrossRef]

26. Vicente, J.; De Carvalho, M.G.; Garcia-Rojas, E.E. Fatty Acids Profile of Sacha Inchi Oil and Blends by $1 \mathrm{H}$ NMR and GC-FID. Food Chem. 2015, 181, 215-221. [CrossRef]

27. Scaldaferri, C.A.; Pasa, V.M.D. Production of Jet Fuel and Green Diesel Range Biohydrocarbons by Hydroprocessing of Soybean Oil over Niobium Phosphate Catalyst. Fuel 2019, 245, 446-458. [CrossRef]

28. Asomaning, J.; Mussone, P.; Bressler, D.C. Pyrolysis of Polyunsaturated Fatty Acids. Fuel Process Technol. 2014, 120, 89-95. [CrossRef]

29. Kubátová, A.; Śávová, J.; Seames, W.S.; Luo, Y.; Sadrameli, S.M.; Linnen, M.J.; Baglayeva, G.V.; Smoliakova, I.P.; Kozliak, E.I. Triacylglyceride Thermal Cracking: Pathways to Cyclic Hydrocarbons. Energy Fuels 2012, 26, 672-685. [CrossRef]

30. Soongprasit, K.; Sricharoenchaikul, V.; Atong, D. Pyrolysis of Millettia (Pongamia) Pinnata Waste for Bio-Oil Production using a Fly Ash Derived ZSM-5 catalyst. J. Anal. Appl. Pyrolysis 2019, 139, 239-249. [CrossRef]

31. Xue, X.; Liu, Y.; Wu, L.; Pan, X.; Liang, J.; Sun, Y. Catalytic Fast Pyrolysis of Maize Straw with a Core-Shell ZSM-5@SBA-15 Catalyst for Producing Phenols and Hydrocarbons. Bioresour. Technol. 2019, 289, 121691. [CrossRef] [PubMed]

32. Singh, G.H.K.; Yusup, S.; Quitain, A.T.; Abdullah, B.; Ameen, M.; Sasaki, M.; Kida, T.; Cheah, K.W. Biogasoline Production from Linoleic Acid via Catalytic Cracking over Nickel and Copper-Doped ZSM-5 Catalysts. Environ. Res. 2020, 186, 109616. [CrossRef] [PubMed]

33. Zhang, S.; Zhang, H.; Liu, X.; Zhu, S.; Hu, L.; Zhang, Q. Upgrading of Bio-Oil from Catalytic Pyrolysis of Pretreated Rice Husk over Fe-Modified ZSM-5 Zeolite Catalyst. Fuel Process. Technol. 2018, 175, 17-25. [CrossRef]

34. Ozbay, N.; Yargic, A.S.; Yarbay Sahin, Z.; Yaman, E. Valorization of Banana Peel Waste via In-Situ Catalytic Pyrolysis using Al-Modified SBA-15. Renew. Energy 2019, 140, 633-646. [CrossRef]

35. Rahman, M.M.; Liu, R.; Cai, J. Catalytic Fast Pyrolysis of Biomass over Zeolites for High Quality Bio-Oil-A Review. Fuel Process. Technol. 2018, 180, 32-46. [CrossRef] 
36. Kamaruzaman, M.F.; Taufiq-Yap, Y.H.; Derawi, D. Green Diesel Production from Palm Fatty Acid Distillate over SBA-15-Supported Nickel, Cobalt, and Nickel/Cobalt Catalysts. Biomass Bioenergy 2020, 134, 105476. [CrossRef]

37. Dindi, A.; Quang, D.V.; Vega, L.F.; Nashef, E.; Abu-Zahra, M.R.M. Applications of fly ash for $\mathrm{CO}_{2}$ capture, utilization, and storage. J. CO2 Util. 2019, 29, 82-102. [CrossRef]

38. Soongprasit, K.; Vichaphund, S.; Sricharoenchaikul, V.; Atong, D. Activity of Fly Ash-Derived ZSM-5 and Zeolite X on Fast Pyrolysis of Millettia (Pongamia) Pinnata Waste. Waste Biomass Valoriz. 2020, 11, 715-724. [CrossRef]

39. Engtrakul, C.; Mukarakate, C.; Starace, A.K.; Magrini, K.A.; Rogers, A.K.; Yung, M.M. Effect of ZSM-5 acidity on aromatic product selectivity during upgrading of pine pyrolysis vapors. Catal. Today 2016, 269, 175-181. [CrossRef]

40. Yu, Y.; Li, X.; Su, L.; Zhang, Y.; Wang, Y.; Zhang, H. The role of shape selectivity in catalytic fast pyrolysis of lignin with zeolite catalysts. Appl. Catal. A Gen. 2012, 447-448, 115-123. [CrossRef]

(C) 2020 by the authors. Licensee MDPI, Basel, Switzerland. This article is an open access article distributed under the terms and conditions of the Creative Commons Attribution (CC BY) license (http://creativecommons.org/licenses/by/4.0/). 